\title{
ADESÃO À VALORES MORAIS ENTRE ENVOLVIDOS EM SITUAÇÕES DE BULLYING
}

\author{
MORAL VALUES ADHERENCE AMONG THOSE INVOLVED IN \\ BULLYING SITUATIONS
}

\author{
Luciene Regina Paulino Tognetta ${ }^{1}$ \\ Universidade Estadual Paulista, Araraquara, SP, Brasil \\ Vitória Hellen Holanda Oliveira ${ }^{2}$ \\ Universidade Estadual Paulista, Araraquara, SP, Brasil \\ Sanderli Aparecida Bicudo Bomfim ${ }^{3}$ \\ Universidade Estadual Paulista, Araraquara, SP, Brasil
}

\begin{abstract}
Resumo: Bullying é um fenômeno humano cujas manifestações em forma de humilhações e intimidações sistemáticas, repetitivas, intencionais e entre pares denotam sua complexidade. Do ponto de vista da Psicologia Moral, valores morais como respeito, justiça e solidariedade parecem estar comprometidos nessas situações violentas. Essa pesquisa tem como objetivos constatar a adesão a valores morais - o respeito, a justiça e a solidariedade - por adolescentes que se percebem autores, vítimas e espectadores em situações de bullying. A amostra, escolhida por conveniência, conta com a participação de 2.513 adolescentes de Ensino Fundamental II, de escolas públicas e particulares do Estado de São Paulo. Os resultados comprovam a hipótese inicial de que há diferenças nos modos de adesão a valores morais entre aqueles que se autoperceberem autores, vítimas ou espectadores desse fenômeno.
\end{abstract}

Palavras-chave: Bullying; Valores morais; Adolescentes; Convivência escolar.

\begin{abstract}
Bullying is a human phenomenon whose manifestations in the form of systematic, repetitive, intentional, peer-to-peer humiliation and intimidation demonstrate its complexity. From the point of view of Moral Psychology, moral values such as respect, justice, and solidarity appear to be compromised in these violent situations. This research aims to verify the moral values adherence - respect, justice, and solidarity by teenagers who see themselves as perpetrators, victims, and bystanders in bullying situations. The sample, chosen by convenience, relies on the participation of 2,513 teenagers from Elementary II, attending public and private schools in the state of São Paulo. The results substantiate the initial hypothesis that there are differences in the ways of adherence to moral values among those who self-perceive themselves as perpetrators, victims, or bystanders of this phenomenon.
\end{abstract}

Keywords: Bullying; Moral values; Teenagers; School coexistence.

\footnotetext{
${ }^{1}$ Doutora em Psicologia Escolar e do Desenvolvimento Humano pela Universidade de São Paulo (USP), Professora do Departamento de Psicologia da Educação da Faculdade de Ciências e Letras e do Programa de Pós-Graduação em Educação Escolar. E-MAIL: luciene.tognetta@unesp.br. ORCID: http://orcid.org/0000-0003-0929-4925

2 Graduanda em Pedagogia pela Universidade de São Paulo (USP). E-MAIL: vitoria.hellen@unesp.br. ORCID: http://orcid.org/0000-0003-3430-5585

3 Mestra em Educação Escolar, pela Faculdade de Ciências e Letras (UNESP/Araraquara). E-MAIL: sanderli.bicudo@gmail.com .ORCID: http://orcid.org/0000-0002-7371-5184

Revista Tópicos Educacionais, Pernambuco, v. 27, n. 01, p. 98-119, 2021. ISSN: 2448-0215.

https://periodicos.ufpe.br/revistas/topicoseducacionais/index

Dossiê "Conflitos, violências, bullying na escola: problemas da convivência potencializado pela pandemia?" DOI: 10.51359/2448-0215.2021.250284
} 


\section{Revista Tópicos Educacionais}

\section{Introdução}

Diante de um quadro social de extremismos, intimidações, agressões físicas e virtuais, que se configuram formas de desrespeito e intolerância, parece que a indagação sobre a responsabilidade pela formação das futuras gerações soa ainda mais contundente: o que fazer para que seres humanos sejam mais respeitosos, justos, solidários, tolerantes e democráticos?

As respostas não são fáceis e, portanto, tampouco otimistas. Segundo a teoria construtivista de Piaget (1994), os valores morais são fruto de uma construção progressiva do sujeito que age a partir da interação com o meio em que vive, na escola, na família, na sociedade e com os amigos. A experiência dos conflitos vivenciados e a possibilidade da descentração de pontos de vistas, da vivência democrática no que tange as oportunidades de tomada de decisão por parte de quem age, são segundo o autor, condição para a vida social pautada em valores construídos pelo sujeito e não determinados ou impostos por meio da obediência a uma autoridade externa (PIAGET, 1994).

Por certo, é preciso que a escola seja um ambiente para a criação de práticas que permitam a construção e a aprendizagem de valores morais (MAZZINI; BASTOS, 2016). Para tanto, a cooperação, no sentido piagetiano do termo (PIAGET, 1994) é que torna possível a descentração de pontos de vistas e a tomada de perspectiva do outro para que tal aprendizagem aconteça.

Entretanto, essa mesma escola que tanto se deseja ser espaço de construção de formas mais assertivas de convivência, é palco de inúmeros problemas em seu interior, como diversas pesquisas mostram. O SAEB 2017 (IEDE, 2019) apontou que dos diretores que responderam à pesquisa, 15,8\% indicaram que os alunos portam armas brancas ao frequentarem as aulas. Esta mesma pesquisa revelou que $68 \%$ dos professores respondentes indicaram a indisciplina como um dos dificultadores para a aprendizagem dos alunos e 72,4\% deles indicaram a agressão, seja ela verbal e física, como presente na rotina escolar. Embora sejam dados que nos assustam, outras pesquisas corroboram tais dados.

Abramovay (2016) em outra investigação, constatou que metade dos estudantes alegam já terem sido agredidos na escola e, que 2 em cada 10 estudantes, afirmaram já terem visto armas na escola. A pesquisa da TALIS (Teaching and Learning International Survey), que foca no ensino e aprendizagem na escola básica, apontou dados de 2013 que já indicavam as mesmas situações, $12 \%$ dos diretores escolares que participaram da pesquisa indicaram ofensa verbal ou intimidação a professores ou membros da equipe escolar e $34 \%$ sendo entre alunos semanalmente (OCDE,

Revista Tópicos Educacionais, Pernambuco, v. 27, n. 01, p. 98-119, 2021. ISSN: 2448-0215. https://periodicos.ufpe.br/revistas/topicoseducacionais/index Dossiê "Conflitos, violências, bullying na escola: problemas da convivência potencializado pela pandemia?" DOI: $10.51359 / 2448-0215.2021 .250284$ 
214). Este mesmo estudo, aponta que os professores brasileiros perdem $20 \%$ do tempo mantendo a disciplina. Isso lhes dá o pior lugar nessa categoria da pesquisa, que contou com a participação de 34 países. Certamente, os problemas de convivência na escola são inúmeros, contudo, entre eles, um tem chamado a atenção de pesquisadores já há algum tempo. Inúmeras pesquisas no Brasil (BOMFIM, 2019; LAPA, 2019; SOUZA, 2019; TOGNETTA; AVILÉS MARTÍNEZ; ROSÁRIO, 2016; TOGNETTA; VINHA, 2010) e no mundo (COWIE; WALLACE, 2000; AVILÉS MARTÍNEZ, 2019; OLWEUS, 1993; DEL BARRIO et al., 2003; AVILÉS MARTÍNEZ, 2006a) têm se especializado em apontar características de um fenômeno humano cuja manifestação parece destituída de valores morais. Traçar correspondências que possam afirmar tal constatação é o objetivo maior desta investigação.

\subsection{Bullying}

O bullying é um fenômeno que, inúmeras vezes, tem sido confundido com outros problemas, de certa forma até mais recorrentes nas escolas, como as indisciplinas (transgressões às regras escolares, insubordinação e rebeldia) e incivilidades (transgressões às normas de conduta e impolidez). No entanto, apesar de não ser o mais frequente, é o fenômeno que mais afeta as representações de si de crianças e adolescentes, incidindo negativamente na construção de sua identidade, culminando em problemas de personalidade e baixa autoestima (LA TAILLE, 2002; TOGNETTA, 2005a).

Bullying vem da palavra inglesa "bully", que significa "valentão" e tem como características próprias a sua paridade, ou seja, acontece entre pessoas da mesma hierarquia como, aluno/aluno, professor/professor, em ações repetitivas. Ocorre, em sua maioria, escondido aos olhos das autoridades e há a intenção de ferir um alvo que se sente de menor valor, configurando um desequilíbrio de poder psicológico entre autor e alvo. E, por fim, acontece na presença de espectadores (TOGNETTA, 2005a; TOGNETTA, 2005b; TOGNETTA; VINHA, 2008).

Dentre tantas óticas pelas quais o bullying pode ser analisado e compreendido, é preciso constatar que o bullying é também um problema de caráter moral (TOGNETTA; AVILÉS MARTÍNEZ; ROSÁRIO, 2016), uma vez que nesse tipo de intimidação há ausência de um ou mais valores morais, como a tolerância, o respeito, a generosidade entre outros. Configura-se como um problema moral na medida em que a ideia do "dever" moral de agir de forma adequada, bem como o "querer" ser visto como moral inexistem (LA TAILLE, 2006).

Revista Tópicos Educacionais, Pernambuco, v. 27, n. 01, p. 98-119, 2021. ISSN: 2448-0215. https://periodicos.ufpe.br/revistas/topicoseducacionais/index Dossiê "Conflitos, violências, bullying na escola: problemas da convivência potencializado pela pandemia?" DOI: $10.51359 / 2448-0215.2021 .250284$ 
No Brasil, 29\% dos alunos que participaram do Pisa (Programa Internacional de Avaliação de Estudantes) responderam terem sido alvo de bullying, pelo menos uma vez por mês (OCDE, 2018). Em pesquisa realizada pelo Pesquisa Nacional de Saúde do Escolar (PENSE) (IBGE, 2010), constatou-se que, dentre 618.555 estudantes, 5,4\% dos alunos são intimidados repetidas vezes. Esta mesma pesquisa, em estudos mais recentes (IBGE, 2016), constatou que os números têm aumentado, 7,6\% dos meninos e 7,4\% das meninas sofrem intimidações de maneira recorrente. Outra pesquisa, realizada pelo Centro de Empreendedorismo Social e Administração em Terceiro Setor (CEATS) (FISCHER, 2010), evidenciou que cerca de 20\% dos adolescentes presenciam atos de intimidação e/ou violência no ambiente escolar, de maneira repetitiva. Em pesquisa realizada por Lapa (2019), investigou-se 2.513 adolescentes do Ensino Fundamental II. Destes, $16,40 \%$ se autodenominam como alvos de bullying, $12,62 \%$ como autores e $46,56 \%$ como espectadores.

Se numa intimidação há, necessariamente, esses três papéis distintos, analisemos suas características para melhor compreensão do fenômeno.

Os alvos de bullying têm revelado características como solidão, sofrimento físico e/ou psicológico, submissão, depressão, ansiedade social e autoestima negativa (OLWEUS, 1993; SOUZA, 2019). Apesar deles serem os que mais se preocupam com sua autoimagem (SAGONE; LICATA, 2009), eles não se veem com valor (OLWEUS, 1997) e sentem-se merecedores dos maus tratos que sofrem (GRAHAM; JUVONEN, 1998; TOGNETTA, 2012; AVILÉS MARTÍNEZ, 2013). Numa investigação conduzida por Tognetta e Rosário (2013) indicou-se que do ponto de vista moral, os alvos de bullying podem ser individualistas, mas também admiradores de conteúdos éticos, tendo em vista que possuem uma imagem de si empobrecida diante dos outros, fazendo com que se sintam inferiores às qualidades dos grupos aos quais pertencem. Os autores ainda afirmam que "[...] entre aqueles que se distinguem como alvos em situações de bullying, formas de desengajamento moral que se destacam: a atribuição de culpa e a desumanização como justificativas para o fato de confirmar a violência como um valor.” (p. 129).

Em pesquisas anteriores sobre as vítimas (HODGES; PERRY, 1996; SALMIVALLI; ISAACS, 2005; TOGNETTA; ROSÁRIO, 2013; BOMFIM; TOGNETTA, 2016; TOGNETTA et al., 2017), vimos que elas possuem déficits em habilidades sociais, estratégias de enfrentamento, assertividade, regulação emocional e insegurança sobre si mesmo, ou seja, carecem de reconhecimento de seus próprios estados emocionais, contudo, não lhes faltam a adesão a valores

Revista Tópicos Educacionais, Pernambuco, v. 27, n. 01, p. 98-119, 2021. ISSN: 2448-0215. https://periodicos.ufpe.br/revistas/topicoseducacionais/index

Dossiê "Conflitos, violências, bullying na escola: problemas da convivência potencializado pela pandemia?" DOI: $10.51359 / 2448-0215.2021 .250284$ 
morais. Por fim, alvos podem apresentar o que as pesquisas chamam de "blank face" nas situações de intimidação, que é a denotação de um rosto inexpressivo, indicando a falta de autoconhecimento sobre suas próprias emoções (BEERDONDINI; DONDI, 1999).

Os autores de bullying têm sua inteligência bem desenvolvida, mas apresentam baixa empatia (OLWEUS, 1993; SMITH et al., 1993; SÁNCHEZ; ORTEGA; MENESINI, 2012; MENESINI et al., 2003; CARAVITA; DI BLASIO; SALMIVALLI, 2009) e "maquiavelismo" (SUTTON; SMITH; SWETTENHAM, 1999; GINI, 2006), têm competência moral para julgar, mas falham em compaixão moral e sensibilidade (GINI; POZZOLI; HAUSER, 2011). Menesini et al. (2003) denominaram essa baixa sensibilidade à dor alheia como indiferença, como a ausência de sentimentos negativos ou até de culpa ao se causar dano à outrem. Outros autores (MENESINI; CAMODECA, 2008; GARAIGORDOBIL; OÑEDERA, 2009) também encontraram nos autores essa falta de culpa e ainda verificaram a ausência de vergonha em situações de intimidação.

Em estudos anteriores, foi possível verificar que os agressores têm como motivação para seus comportamentos hostis, a realização, busca pelo poder, status e posição dominante entre seus pares. (PELLEGRINI, 2002; SALMIVALLI; PEETS, 2008; SOUZA, 2019). Já Tognetta e Rosário (2013), ao investigarem as representações que os envolvidos em intimidações têm de si mesmos, verificaram que autores de bullying têm representações de si individualistas.

Se em situações de maus tratos há de um lado autores e do outro os alvos, há que se considerar o personagem que se constitui como maioria entre os envolvidos: os espectadores. Esses são cerca de $60 \%$ a $80 \%$ dos alunos (AVILÉS MARTÍNEZ, 2006b). Eles sabem das características de tais intimidações (TOGNETTA; BOZZA, 2010; TOGNETTA, 2011; AVILÉS MARTÍNEZ, 2013), porém sem concordarem com as situações de maus tratos (RIGBY; SLEE, 1993; CHARACH; PEPLER; ZIEGLER, 1995). Salmivalli (2010) verificou que eles gostariam de fazer algo para cessar os maus tratos, mas não o fazem ou por medo se serem a próxima vítima (CHAUX, 2012) ou pelo objetivo de manterem o status perante o grupo (SALMIVALLI et al., 1996; JUVONEN; GALVAN, 2008) com o objetivo maior de serem como os colegas de turma mais populares (HAWKINS; PEPLER; CRAIG, 2001).

Ao aprofundar o olhar sobre esse tipo de envolvido em bullying, Salmivalli et al. (1996) identificou quatro grupos diferentes de espectadores. No primeiro grupo posicionam-se como assistentes, ajudando o(s) autor(es) em suas atitudes; no segundo há os reforçadores que não participam de forma direta na intimidação, mas que assumem posturas e gestos que colaboram,

Revista Tópicos Educacionais, Pernambuco, v. 27, n. 01, p. 98-119, 2021. ISSN: 2448-0215. https://periodicos.ufpe.br/revistas/topicoseducacionais/index Dossiê "Conflitos, violências, bullying na escola: problemas da convivência potencializado pela pandemia?" DOI: $10.51359 / 2448-0215.2021 .250284$ 
como ovacionar, filmar e aplaudir. O terceiro grupo identificado são os observadores com atitudes que não validam ou desvalidam o autor e suas ações, mas ignoram a situação, como se não lhe competisse fazer algo. Finalmente, o quarto grupo é aquele constituído pelos que se colocam a favor da vítima, defendendo-as.

Assim, os envolvidos em uma situação de vitimização convivem com a ausência de um conteúdo moral. Passemos a tratar deste assunto.

\subsection{Valores morais}

Segundo Mazzini e Bastos (2016), valores morais são horizontes normativos considerados bons para a vivência em sociedade. São parâmetros para guiar nosso modo de ser e viver em sociedade de modo a estarmos de acordo com costumes, normas e princípios estabelecidos, que nos indicam as ações e atitudes certas, boas e justas (MARQUES; TAVARES; MENIN, 2017).

Jares (2008) afirma que a ausência do respeito nas relações interpessoais torna a convivência impossível, ou ao menos, a torna uma convivência violenta e não democrática. Portanto, o respeito se configura numa qualidade básica e inegociável que fundamenta a convivência em um plano de igualdade, a fim de se assegurar a dignidade humana.

Segundo Jares (2008), a solidariedade é uma qualidade do ser humano que nos leva a partilhar sentimentos. Nesse sentido, somos solidários quando nos sensibilizamos com a dor do outro, pelo que padece, pelo que carece de algumas necessidades e pelo que sofre alguma injustiça (JARES, 2008). A solidariedade é um instrumento de melhoria da convivência, tendo em vista que ao sermos solidários, incluímos o outro em nosso universo de valores e consideramos o seu bem.

Por sua vez, a justiça pressupõe um compromisso com a mudança, seja ela social, política, econômica ou cultural. Sendo assim, a justiça se apresenta como um valor central e referência para os demais valores e se pauta em princípios de igualdade e equidade (MENIN; BATAGLIA; MORO, 2013).

Tais discussões reverberam em uma questão fundamental: haverá diferenças entre a forma com que meninos e meninas que se percebem como autores, vítimas ou espectadores em situações de bullying e como aderem aos valores morais da justiça, do respeito e da solidariedade?

Visando responder a essa questão, traçamos como objetivos da presente pesquisa: constatar o modo de adesão a valores morais - o respeito, a justiça e a solidariedade - entre adolescentes que se percebem autores, vítimas e espectadores em situações de bullying e, concomitantemente,

Revista Tópicos Educacionais, Pernambuco, v. 27, n. 01, p. 98-119, 2021. ISSN: 2448-0215. https://periodicos.ufpe.br/revistas/topicoseducacionais/index Dossiê "Conflitos, violências, bullying na escola: problemas da convivência potencializado pela pandemia?" DOI: $10.51359 / 2448-0215.2021 .250284$ 
Revista Tópicos Educacionais

Revista do Programa de Pós-Graduação em Educação

da Universidade Federal de Pernambuco (UFPE)

verificar se há diferenças nesse modo de adesão aos valores morais em adolescentes que se auto identificam nos diferentes papéis desse fenômeno.

Temos por hipótese que há diferenças nos modos de adesão aos valores morais como o respeito, a justiça e a solidariedade entre adolescentes que se auto perceberam participantes, seja como autor, alvo ou espectador em casos de bullying.

\section{MÉTODO}

A presente pesquisa é de caráter descritivo e exploratório, pois visa descrever características e fornecer proximidade com o objeto de estudo.

Esta pesquisa ${ }^{4}$ se constitui no desdobramento de uma pesquisa maior do GEPEM UNESP/UNICAMP (Grupo de Estudos e Pesquisas em Educação Moral) - "Bullying: mecanismos psicológicos e intervenção ao problema", coordenado pela Prof. ${ }^{a}$ Dr. ${ }^{a}$ Luciene Regina Paulino Tognetta, que pertence ao eixo de investigação "Estratégias de intervenção: Sistemas de Apoio entre Iguais". Os dados dessa pesquisa anterior foram publicados por Bomfim (2019). A autora autorizou a utilização dos dados para novas análises dos dados coletados.

Figura 1 - Nossas pesquisas (2015-2018)

\footnotetext{
${ }^{4}$ A pesquisa teve autorização do Comitê de Ética da Faculdade de Ciências e Letras da UNESP, sob número CAAE 65373417.0.0000.5400.

Revista Tópicos Educacionais, Pernambuco, v. 27, n. 01, p. 98-119, 2021. ISSN: 2448-0215.

https://periodicos.ufpe.br/revistas/topicoseducacionais/index

Dossiê "Conflitos, violências, bullying na escola: problemas da convivência potencializado pela pandemia?" DOI: $10.51359 / 2448-0215.2021 .250284$ 
Revista Tópicos Educacionais

Revista do Programa de Pós-Graduação em Educação da Universidade Federal de Pernambuco (UFPE)

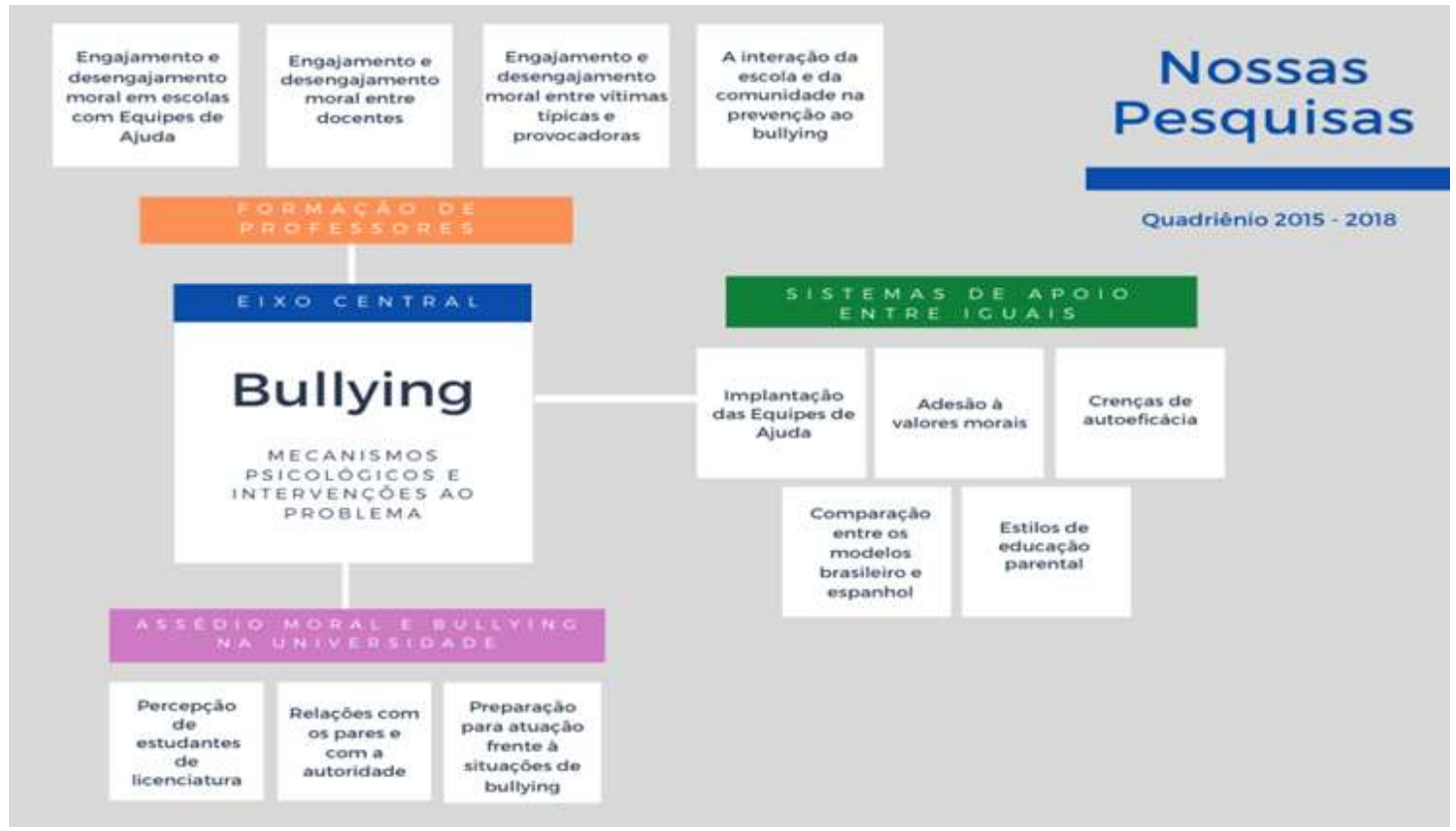

Fonte: GEPEM - Grupo de Estudos e Pesquisas em Educação Moral.

Foi escolhida uma amostra por conveniência, em escolas públicas e particulares do Estado de São Paulo (Campinas, São Paulo, São João da Boa Vista, Santa Bárbara d'Oeste, Itapira, Nova Odessa, Santo André e Ribeirão Preto), destas, 1.366 alunos pertencem a uma escola com um Sistema de Apoio entre Iguais implementado e 1.147 alunos de escolas sem esse sistema, totalizando 2.513 adolescentes entre 11 e 15 anos, de Ensino Fundamental II (BOMFIM, 2019; LAPA, 2019; SOUZA, 2019).

O instrumento utilizado na referida dissertação foi um questionário adaptado da Fundação Carlos Chagas, composto por perguntas fechadas e dividido em duas partes, preenchido na versão on-line, na plataforma Survey Monkey. A primeira parte englobou questões de caracterização, na qual os alunos preencheram questões relacionadas à idade e à frequência de bullying. A segunda parte contou com uma adaptação do instrumento validado pela Fundação Carlos Chagas (TOGNETTA; MENIN, 2017), que investigou a adesão aos valores morais da justiça, respeito, solidariedade e convivência democrática, através de situações hipotéticas cujas alternativas apontavam contra-valores e pró-valores. (MENIN; BATAGLIA; MORO, 2013).

As histórias apresentadas no instrumento continham cinco opções de resposta e os respondentes só podiam escolher uma delas. As alternativas evidenciam modos diferentes de aderir aos valores do respeito, da justiça e da solidariedade: duas (C1 e $\mathrm{C} 2)$, indicavam contra-

Revista Tópicos Educacionais, Pernambuco, v. 27, n. 01, p. 98-119, 2021. ISSN: 2448-0215. https://periodicos.ufpe.br/revistas/topicoseducacionais/index Dossiê "Conflitos, violências, bullying na escola: problemas da convivência potencializado pela pandemia?" DOI: $10.51359 / 2448-0215.2021 .250284$ 
valores, ou seja, a não adesão a um valor moral, sendo C1 em uma perspectiva social egocêntrica e C2 em uma perspectiva social sociocêntrica.

Três alternativas indicavam adesão a um valor moral, sendo P1 a adesão sob uma perspectiva social egocêntrica, na qual o indivíduo visa a satisfação das próprias necessidades e considera apenas seu ponto de vista. P2 a adesão em uma perspectiva social sociocêntrica, em que o indivíduo considera em seu universo social apenas pessoas importantes, como familiares e amigos e, a submissão às autoridades, regras e convenções sociais.

E, por fim, P3 sendo a adesão a um valor sob uma perspectiva social moral, que se dá pela compreensão de que há um princípio maior e universal que é bom, justo e necessário para todos. Para a construção dessas histórias, foi utilizada a matriz de cada valor, apresentada a seguir:

Quadro 1. Matriz dos valores

\begin{tabular}{|c|c|}
\hline VALOR & MATRIZ DOS VALORES \\
\hline SOLIDARIEDADE & $\begin{array}{l}\text { Ser solidário é, efetivamente, além do } \\
\text { respeito, partilhar um sentimento de } \\
\text { interdependência, reconhecer a pertinência a } \\
\text { uma comunidade de interesses e de afetos - } \\
\text { tomar para si questões comuns, } \\
\text { responsabilizar-se pessoal e coletivamente } \\
\text { por elas (BRASIL, 1998, p. 104). Há uma } \\
\text { dimensão da solidariedade que se aproxima } \\
\text { mais da generosidade e outra que se } \\
\text { aproxima da cidadania em busca do bem } \\
\text { comum. Em ambos os casos, a solidariedade } \\
\text { inclui a cooperação. }\end{array}$ \\
\hline RESPEITO & $\begin{array}{l}\text { O respeito significa a valorização de toda e } \\
\text { qualquer pessoa considerada em sua } \\
\text { singularidade. Toda e qualquer ação que fira } \\
\text { a dignidade de uma pessoa, como a } \\
\text { violência, a humilhação, a exploração, a } \\
\text { manipulação e várias formas de } \\
\text { discriminação devem ser repudiadas como } \\
\text { desrespeito. }\end{array}$ \\
\hline JUSTIÇA & $\begin{array}{l}\text { A justiça é composta dos princípios de } \\
\text { igualdade e equidade e articula-se com outros } \\
\text { valores morais, como a dignidade, o respeito } \\
\text { e o diálogo. O princípio da igualdade é } \\
\text { fundamental para justiça distributiva, para } \\
\text { estabelecer critérios de atribuição de direitos } \\
\text { e deveres entre todas as pessoas. O mesmo }\end{array}$ \\
\hline
\end{tabular}

Revista Tópicos Educacionais, Pernambuco, v. 27, n. 01, p. 98-119, 2021. ISSN: 2448-0215.

https://periodicos.ufpe.br/revistas/topicoseducacionais/index

Dossiê "Conflitos, violências, bullying na escola: problemas da convivência potencializado pela pandemia?" DOI: $10.51359 / 2448-0215.2021 .250284$ 


\begin{tabular}{|l|l|}
\hline & $\begin{array}{l}\text { ocorre na justiça retributiva em relação à } \\
\text { atribuição de penalidades aos atos injustos, } \\
\text { desrespeitosos e relativos às infrações. }\end{array}$ \\
\hline
\end{tabular}

Fonte: Bomfim (2019) adaptado de Marques, Tavares e Menin (2017).

\section{RESULTADOS E DISCUSSÃO}

\subsection{Sobre a adesão a valores}

A fim de responder aos objetivos traçados em nossa investigação, consideramos em nossa análise como "não adesão a valores morais" as respostas em C1 e C2 (não adesão a um valor moral em perspectiva social egocêntrica e em perspectiva social sociocêntrica, respectivamente). Consideramos como "adesão a um valor moral" as respostas em P3 que asseguram o princípio universal sobre o que é certo, bom e justo para todos. Excluímos desta análise as respostas em P1 e P2 pois, ainda que caracterizem uma adesão aos valores, apontam uma adesão "empobrecida", tendo em vista suas perspectivas egocêntricas e sociocêntricas, respectivamente.

\subsection{Sobre a constatação dos envolvidos em situações de bullying}

Dentre os 2.126 respondentes, 11,52\% estão envolvidos em situações de bullying, seja como autor, alvo ou espectador. Ou seja, independentemente do papel que assumem em casos de bullying, esses $11,52 \%$ já experienciaram na escola situações em que essa forma de intimidação acontece.

\subsection{As correspondências: participação na vitimização $X$ adesão aos valores morais}

\subsubsection{Bullying X Respeito}

Constatamos uma diferença significativa de adesão ao valor do respeito entre aqueles que participam, seja como autor, como alvo ou como espectador, em comparação com apenas os espectadores. Apenas 59,18\% dos participantes (autor, alvo ou espectador) aderiram ao valor do respeito, contra $73,4 \%$ dos espectadores. Constatamos também uma diferença significativa entre os que participam, de modo geral, das situações de bullying $(59,18 \%)$ e aqueles que não participam, ou seja, que não se identificaram enquanto autores, vítimas ou espectadores (72,05\%): os que não se identificam como participantes de situações de intimidação aderem mais ao respeito do que os que participam diretamente dessas ações.

Revista Tópicos Educacionais, Pernambuco, v. 27, n. 01, p. 98-119, 2021. ISSN: 2448-0215. https://periodicos.ufpe.br/revistas/topicoseducacionais/index Dossiê "Conflitos, violências, bullying na escola: problemas da convivência potencializado pela pandemia?" DOI: $10.51359 / 2448-0215.2021 .250284$ 
As vítimas, por outro lado, apresentaram taxas menores de adesão ao valor do respeito em situações de bullying $(67,24 \%)$, se comparado aos outros valores.

\subsubsection{Bullying X Justiça}

Quanto à adesão da justiça, as vítimas têm apresentado maior adesão, 81,03\%, seguidos dos espectadores, com 76,08\% e dos que não têm nenhum envolvimento em situações de bullying, com 75,14\%. Logo, o grupo que se apresenta com menor adesão ao valor da justiça é o dos autores, com apenas $66,67 \%$ de adesão em níveis mais elevados.

\subsubsection{Bullying X Solidariedade}

O valor da solidariedade é o que possui maiores taxas de adesão. Por hipótese, acreditamos que, na faixa etária pesquisada - adolescentes de 11 a 15 anos -, os jovens estão entrando no "limiar da vida adulta" (GILLIGAN, 2011 apud BOMFIM, 2019), em que o grupo começa a ter importância em seu universo de valores, aprende-se a ouvir e a ponderar as possibilidades visando o bem comum. É considerada a fase dos sentimentos ideais que levam em consideração os ideais coletivos, favorecendo a construção da personalidade que, segundo Piaget (1980/2002), implica a cooperação e a sua inserção na vida adulta (BOMFIM, 2019). Somada a essa explicação, os resultados das investigações conduzidas anteriormente também encontraram maior adesão à solidariedade nos estudos com populações diferentes, o que permitiu aos pesquisadores também a hipótese de que as histórias hipotéticas construídas se relacionam mais às questões de assistência e ajuda do que propriamente demonstram ou conseguem avaliar uma dimensão mais profunda da solidariedade como forma de compaixão e generosidade (MENIN; TAVARES; MORO, 2013; MENIN; BATAGLIA; MORO, 2013; TAVARES et al., 2016; MARQUES; TAVARES; MENIN, 2017; TOGNETTA; MENIN, 2017)

O grupo que mais adere ao valor da solidariedade é o das vítimas, com 89,66\% de adesão. Logo em seguida temos o grupo sem nenhuma participação em situações de intimidação, 86,66\% e os espectadores, com $85,14 \%$, respectivamente. E, por fim, o grupo que menos adere ao valor da solidariedade: os autores, com $72,92 \%$ de adesão.

\subsubsection{Bullying X Respeito, Justiça e Solidariedade}

Revista Tópicos Educacionais, Pernambuco, v. 27, n. 01, p. 98-119, 2021. ISSN: 2448-0215. https://periodicos.ufpe.br/revistas/topicoseducacionais/index Dossiê "Conflitos, violências, bullying na escola: problemas da convivência potencializado pela pandemia?" DOI: 10.51359/2448-0215.2021.250284 
Revista Tópicos Educacionais

Revista do Programa de Pós-Graduação em Educação

da Universidade Federal de Pernambuco (UFPE)

Como podemos constatar na tabela e gráficos a seguir, os autores de bullying são os que menos aderem aos valores morais do respeito, da justiça e da solidariedade, seguidos daqueles que possuem uma participação em situações de bullying, independente do papel que assumem no fenômeno. Já os que mais aderem aos valores são as vítimas, o que faz sentido por não participarem como agressores, nem como espectadores (haja vista que há a possibilidade de espectadores não intervirem em situações de bullying). Em seguida temos aqueles sem nenhuma participação nos casos de bullying e os espectadores, respectivamente.

Tabela 1. Adesão aos valores nos grupos pesquisados

\begin{tabular}{|l|c|c|c|}
\hline & RESPEITO & JUSTIÇA & SOLIDARIEDADE \\
\hline AUTORES & $64,58 \%$ & $66,67 \%$ & $72,92 \%$ \\
\hline VÍTIMAS & $67,24 \%$ & $81,03 \%$ & $89,66 \%$ \\
\hline ESPECTADORES & $73,40 \%$ & $76,08 \%$ & $85,14 \%$ \\
\hline NENHUMA & $72,05 \%$ & $75,14 \%$ & $86,66 \%$ \\
PARTICIPAÇÃO & & & \\
\hline
\end{tabular}

Fonte: Elaborado pelas autoras.

Na Imagem1 podemos visualizar os valores e os sujeitos em comparação.

Imagem 1. Gráfico da adesão aos valores nos grupos pesquisados

Revista Tópicos Educacionais, Pernambuco, v. 27, n. 01, p. 98-119, 2021. ISSN: 2448-0215.

https://periodicos.ufpe.br/revistas/topicoseducacionais/index

Dossiê "Conflitos, violências, bullying na escola: problemas da convivência potencializado pela pandemia?" DOI: $10.51359 / 2448-0215.2021 .250284$ 
Revista Tópicos Educacionais

Revista do Programa de Pós-Graduação em Educação

da Universidade Federal de Pernambuco (UFPE)

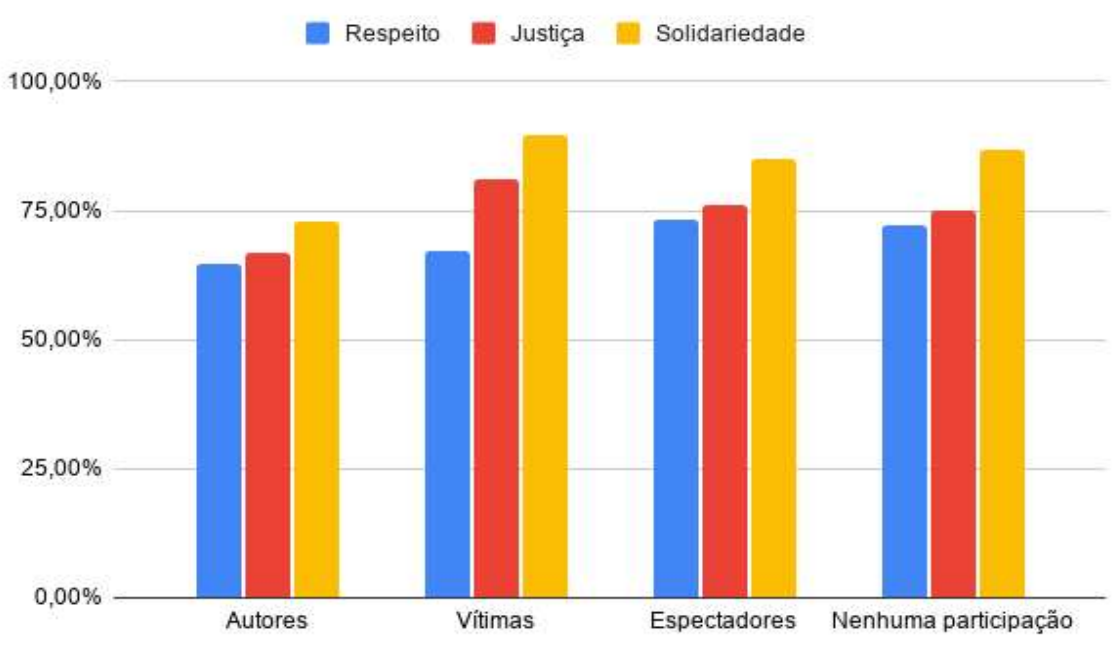

Fonte: Elaborado pelas autoras.

Apesar das diferenças de adesão aos valores, nota-se que os níveis de adesão se mostram bastante representativos. Como em estudos anteriores (MENIN; TAVARES; MORO, 2013; MENIN; BATAGLIA; MORO, 2013; TAVARES et al., 2016; MARQUES; TAVARES; MENIN, 2017; TOGNETTA; MENIN, 2017) as limitações do instrumento podem explicar este fato visto que as situações hipotéticas tratam dos juízos e não das ações propriamente ditas.

Com o auxílio do Imagem 2, é possível traçar mais algumas análises quando correspondemos a participação nas situações de vitimização e a adesão a valores quando separamos os tipos de dilemas de respeito que evidenciam situações hipotéticas em que há bullying e quando não há. Vejamos os resultados.

Imagem 2. Gráfico da adesão aos valores nos grupos pesquisados

Revista Tópicos Educacionais, Pernambuco, v. 27, n. 01, p. 98-119, 2021. ISSN: 2448-0215.

https://periodicos.ufpe.br/revistas/topicoseducacionais/index

Dossiê "Conflitos, violências, bullying na escola: problemas da convivência potencializado pela pandemia?" DOI: $10.51359 / 2448-0215.2021 .250284$ 


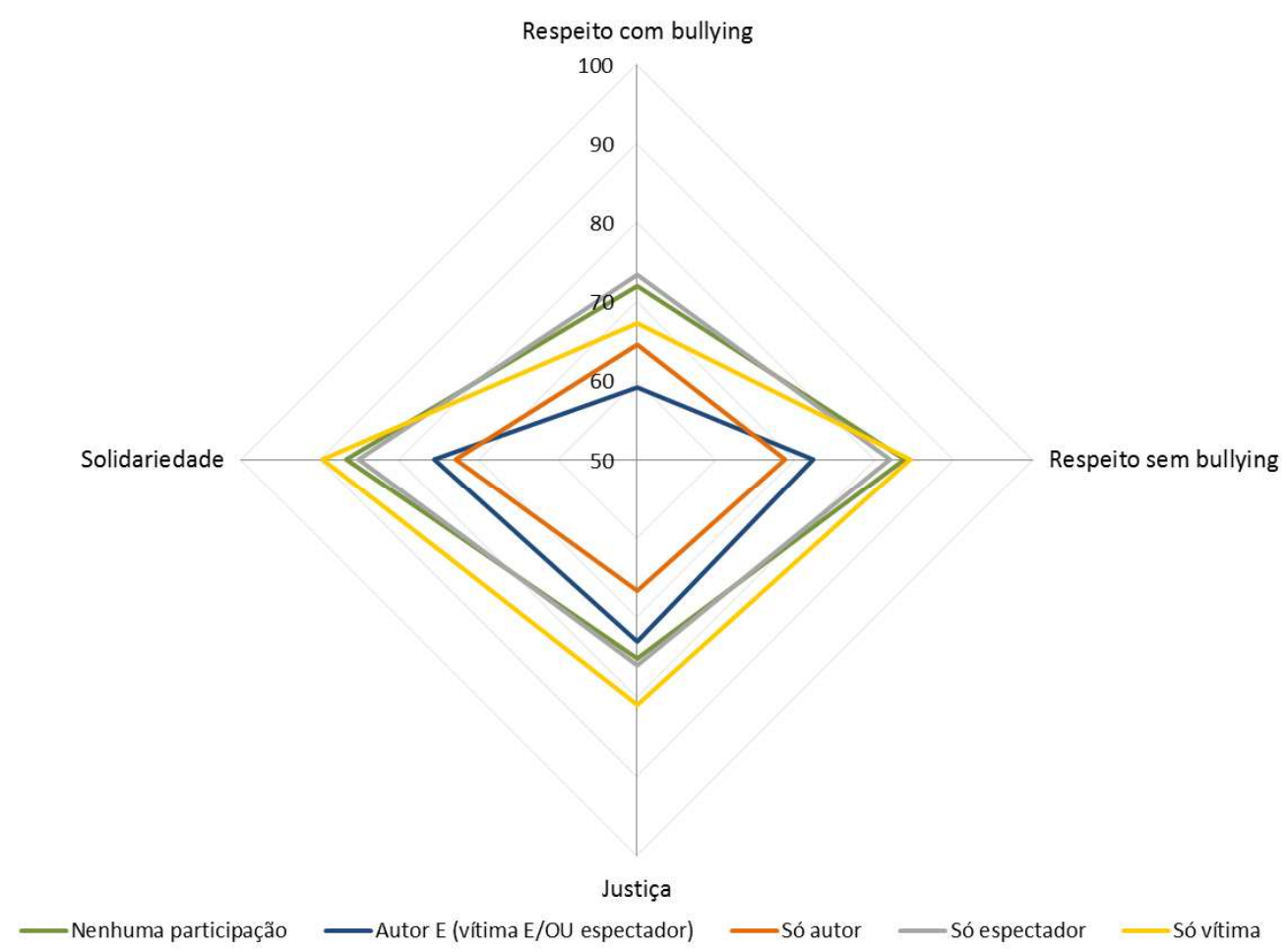

Fonte: Elaborado pelas autoras.

Há resultados que nos parecem interessantes: aqueles que se autopercebem como autores e/ou vítimas e/ou espectadores, portanto, participantes em situações de vitimização tendem a menos aderir ao valor do respeito quando as situações tratam especificamente sobre bullying. Note-se que as vítimas (aquelas que se autopercebem somente como vítimas) seguem o mesmo caminho. A contraposição entre o valor do respeito em situações de humilhação entre pares e como se percebem como participantes de situações como as narradas pode indicar exatamente a explicação para tal: envolver-se em situações de bullying parece implicar a "falta de respeito" como um valor a ser incorporado na identidade do sujeito. E, se estivermos corretos, como em pesquisas anteriores, perceber-se enquanto vítima pode corresponder ao fato de certo "merecimento" pela ausência do respeito (GRAHAM; JUVONEM, 1998; TOGNETTA, 2012; AVILÉS MARTÍNEZ, 2013; TOGNETTA; ROSÁRIO, 2013). As vítimas de bullying tem como uma de suas características a autoestima negativa (TOGNETTA, 2012; AVILÉS MARTÍNEZ, 2013). Devido a isso, as vítimas demonstram déficits em habilidades sociais, resolução de conflitos, estratégias de enfrentamento, assertividade e regulação emocional (TOGNETTA et al.,

Revista Tópicos Educacionais, Pernambuco, v. 27, n. 01, p. 98-119, 2021. ISSN: 2448-0215. https://periodicos.ufpe.br/revistas/topicoseducacionais/index Dossiê "Conflitos, violências, bullying na escola: problemas da convivência potencializado pela pandemia?" DOI: $10.51359 / 2448-0215.2021 .250284$ 
2017). Segundo Jares (2008, p. 32, grifo do autor), “Fazer-se respeitar' tem a ver precisamente com não se deixar intimidar; sofrer abuso ou outro tipo de violência”.

Por sua vez, autores de bullying, são aqueles que menos aderem a quaisquer que sejam os valores e situações em que esses são ausentes. Evidencia-se que entre os autores de bullying lhes falta o que chamamos de "sensibilidade moral" (TOGNETTA; VINHA, 2010; TOGNETTA, 2012). Os autores de bullying têm se mostrado deficientes em suas escolhas morais. Do ponto de vista social-cognitivo, são indivíduos caracterizados pela chamada "cognição-fria", pois possuem boa inteligência social, boa teoria das habilidades mentais e maquiavelismo (SUTTON; SMITH; SWETTENHAM, 1999; GINI, 2006). Eles são hábeis em compreender os estados de espírito de outras pessoas, explorando isso a seu favor, para manipular crenças e emoções (TOGNETTA et al., 2017). Portanto, são os mais desengajados em situações de bullying (GINI, 2006; ALMEIDA; CORREIA; MARINHO, 2010), porque quando têm a possibilidade de escolher entre agir bem e agir mal, optam por agir mal. Isso pois, na hierarquia de valores dos autores são centrais valores amorais como o poder, o sucesso, a realização etc., enquanto os valores morais são periféricos, não sendo suficientes para impulsionar atitudes morais (TOGNETTA et al., 2017).

Durante nossa análise um fato chamou-nos a atenção, apesar de não estar delimitado em nossos objetivos: a questão de gênero e os papéis que os diferentes personagens assumem em situações de bullying. Isso pois, os dados apontaram uma diferença significativa entre o sexo masculino e o sexo feminino: $81,25 \%$ dos autores de bullying são do sexo masculino, enquanto apenas $18,75 \%$ são do sexo feminino. Indaga-se: será que a forma com que os meninos são tratados e educados pela sociedade influencia na forma como se comportam em situações de intimidação? Enquanto isso, a maior porcentagem de espectadores se concentra no sexo feminino, sendo 55,27\%, contra 44,73\% dos meninos. Podemos constatar o olhar atento das meninas frente às situações de intimidação, ameaças e agressões? Haverá uma ligação entre a "ética do cuidado" (GILLIGAN, 1982) e suas participações como espectadoras em casos de bullying?

Já na análise das vítimas, ambos os sexos, feminino e masculino, sofrem maus-tratos, agressões e intimidações, sendo $50 \%$ do sexo feminino e $50 \%$ do sexo masculino. É certo que nossa pesquisa nos deu um sinal sobre uma diferença significativa nas questões de gênero que merecem ser fruto de investigações e discussões futuras. Pretendemos futuramente considerar os aspectos subjetivos da sociedade nas análises de situações de bullying discutindo em que nível a

Revista Tópicos Educacionais, Pernambuco, v. 27, n. 01, p. 98-119, 2021. ISSN: 2448-0215. https://periodicos.ufpe.br/revistas/topicoseducacionais/index Dossiê "Conflitos, violências, bullying na escola: problemas da convivência potencializado pela pandemia?" DOI: $10.51359 / 2448-0215.2021 .250284$ 
meritocracia, as questões de gênero, questões de raça, entre outras, influenciam na construção da personalidade pelos sujeitos, logo, nas relações de convivência nas escolas.

\section{CONSIDERAÇÕES FINAIS}

Os dados de nosso estudo nos possibilitaram comprovar hipóteses apresentadas nas literaturas atuais sobre bullying. Como vimos anteriormente, dentre os protagonistas do fenômeno bullying, os autores são os que apresentam menores taxas de adesão aos valores do respeito $(64,58 \%)$, da justiça $(66,67 \%)$ e da solidariedade $(72,92 \%)$ quando comparados aos demais agrupamentos de participantes de situações de intimidação sistemática. Vimos que vítimas de bullying são as que, em nossa pesquisa, mais aderem aos valores da solidariedade e da justiça, exceto ao respeito e, principalmente, quando se trata em particular de situações hipotéticas que referem-se a ausência desse valor exatamente em situações do tipo particular de violência que é o bullying. Tais constatações podem se dever ao fato de, em situações de intimidação, os alvos se verem com menos valor, ou seja, consentem, ainda que inconscientemente, com as agressões que sofrem (TOGNETTA; ROSÁRIO, 2013). Nota-se que a adesão ao valor do respeito em situações de bullying é baixa entre os alvos desse fenômeno (67,24\%). Contudo, apresentam altos índices de adesão aos valores da justiça (81,03\%) e da solidariedade (89,66\%). Em pesquisas anteriores, essa última virtude fora constatada como característica principal daqueles que mais ajudam (SOUZA, 2019) e, se nossas hipóteses estiverem corretas, dos que já passaram por situações de intimidação na própria pele.

Já os espectadores possuem boas taxas de adesão aos valores morais do respeito, da justiça e da solidariedade, respectivamente, $(73,40 \%, 76,08 \%$ e $85,14 \%)$, se comparado ao grupo dos autores $(64,58 \%, 66,67 \%$ e $72,92 \%)$, por exemplo. Esse grupo tem se mostrado bom agente de mudanças, podendo cobrar, denunciar e ajudar aqueles que, por inúmeras razões, não conseguiram ainda aderir a um valor moral ou à autoconfiança necessária para a vida em sociedade (TOGNETTA et al., 2017). São indivíduos cujas condutas pró-sociais têm a possibilidade de ajudar os colegas. Espectadores de bullying possuem boa compreensão moral e baixos níveis de desengajamentos morais (TOGNETTA; ROSÁRIO, 2013)

Concluímos nossa investigação com a comprovação de nossa hipótese inicial: há diferenças nos modos de adesão aos valores morais entre aqueles que se auto perceberam autores, vítimas ou espectadores desse fenômeno. Tais resultados apontam a importância de uma educação em valores

Revista Tópicos Educacionais, Pernambuco, v. 27, n. 01, p. 98-119, 2021. ISSN: 2448-0215. https://periodicos.ufpe.br/revistas/topicoseducacionais/index Dossiê "Conflitos, violências, bullying na escola: problemas da convivência potencializado pela pandemia?" DOI: $10.51359 / 2448-0215.2021 .250284$ 
voltada ao desenvolvimento da autonomia moral e a promoção de uma convivência ética. Certamente, o ambiente escolar é palco das relações sociais, portanto seus membros devem, "por meio de suas ações, dar exemplos de respeito, justiça, solidariedade, diálogo, cooperação, mais do que fazer discursos ou agir de forma não condizente com os valores que querem ensinar" (MENIN; TAVARES, 2013, p. 15).

Indicam também o imperativo de que as instituições educacionais se valham de propostas sistematizadas e intencionais que proporcionem a aprendizagem dessa convivência pacífica.

Nossas investigações no campo da educação moral têm comprovado a eficácia de estratégias de protagonismo como metodologias que permitem a ação de adolescentes e jovens na promoção da convivência nas instituições escolares (BOMFIM, 2019; LAPA, 2019; SOUZA, 2019). Reafirmamos a importância de que o ambiente escolar possibilite a construção dos valores morais, de vínculos entre os membros, vínculos pautados na prática do diálogo e do exercício da cidadania quando alunos e alunas têm possibilidade de tomar de decisões, participar ativamente na elaboração das regras, a fim de que aprendam a considerar em seu universo de valores, o bem a si e ao outro e a fim de superar a cultura individualista, competitiva e pouco ética que tem imperado em nosso meio em tempos atuais.

\section{REFERÊNCIAS}

ABRAMOVAY, M. (Org.). Diagnóstico participativo das violências nas escolas: falam os jovens. Rio de Janeiro: FLACSO, OEI, MEC, 2016.

ALMEIDA, A.; CORREIA, I.; MARINHO, S. Moral disengagement, normative beliefs of peer group, and attitudes regarding roles in bullying. Journal of School Violence, v. 9, n. 1, p. 23-36, 2010 .

AVILÉS MARTíNEZ, J. M. Bullying: el maltrato entre iguales. Agresores, víctimas y testigos en la escuela. Salamanca: Amarú, 2006a.

AVILÉS MARTÍNEZ, J. M. Bullying: guia para educadores. Trad. Guillermo MIlán-Ramos. rev. Luciene Regina Paulino Tognetta. Campinas, SP: Mercado de Letras, 2013. (Coleção: Psicologia e Educação em debate)

AVILÉS MARTÍNEZ, J. M. Diferencias de atribuición causal en el bullying entre sus protagonistas. Revista Electrónica de Investigación Psicoeducativa, n. 9, v. 4, p. 201-220, 2006 b.

AVILÉS MARTÍNEZ, J. M. Os sistemas de apoio entre iguais. Americana: Ed. Adonis, 2019.

Revista Tópicos Educacionais, Pernambuco, v. 27, n. 01, p. 98-119, 2021. ISSN: 2448-0215. https://periodicos.ufpe.br/revistas/topicoseducacionais/index Dossiê "Conflitos, violências, bullying na escola: problemas da convivência potencializado pela pandemia?" DOI: $10.51359 / 2448-0215.2021 .250284$ 
BERDONDINI, L.; DONDI, M. How do bullies, victims and bystanders react during a session of group work? In: European Conference on Developmental Psychology, 9., 1999, Spetses. Proceedings [...]. Spetses, Grecia, 1999.

BOMFIM, S. A. B. Respeito, justiça e solidariedade no coração de quem ajuda: valores morais e protagonismo entre alunos para combater o bullying. 2019. 210 f. Dissertação (Mestrado em Educação Escolar) - Faculdade de Ciências e Letras, Universidade Estadual Paulista, Araraquara, 2019. Disponível em: https://repositorio.unesp.br/handle/11449/181390. Acesso em: 10 dez. 2020.

BOMFIM, S. A. B.; TOGNETTA, L. R. P. Bullying: un estudio sobre la adhesión a los valores morales y el protagonismo juvenil. European Journal of Education and Psychology, 2016.

BRASIL. Ministério da Educação. Parâmetros curriculares nacionais: temas transversais, ética. Brasília, DF: MEC/Secretaria de Educação Fundamental, 1998.

CARAVITA, S. C. S.; DI BLASIO, P.; SALMIVALLI, C. Unique and interactive effects of empathy and social status on involvement in bullying. Social Development, v. 18, n. 1, p. 140$163,2009$.

CHARACH, A.; PEPLER, D.; ZIEGLER, S. Bullying at school. Education Canada, n. 37, p. 12$18,1995$.

CHAUX, E. Educación, convivencia y agresión escolar. Bogotá, Colômbia: Ediciones Uniandes, 2012.

COWIE, H.; WALLACE, P. Peer suport in action. Londres: Sage Publications, 2000.

DEL BARRIO, C. et al. Representaciones acerca del maltrato entre iguales, atribuciones emocionales y percepción de estrategias de cambio a partir de un instrumento narrativo: Scan bullying. Infancia y Aprendizaje, 2003.

FISCHER, R. M. (Coord.) Bullying escolar no Brasil. In: Relatório final. São Paulo: CEATS/FIA, 2010.

GARAIGORDOBIL, M.; OÑEDERA, J. A. La violencia entre iguales: revisión teórica y estrategias de intervención. Madri: Pirámide, 2009.

GILLIGAN. C. Uma voz diferente. Rio de Janeiro: Ed. Rosa dos Tempos, 1982.

GINI, G. POZZOLI, T. HAUSER, M. Bullies have enhanced moral competence to judge relative to victims, but lack moral compassion. Personality and Individual Differences, v. 50, n. 5, p. 603-608, 2011.

GINI, G. Social cognition and moral cognition in bullying: what's wrong? Aggressive behavior, v. 32, p. 528-539, 2006.

Revista Tópicos Educacionais, Pernambuco, v. 27, n. 01, p. 98-119, 2021. ISSN: 2448-0215. https://periodicos.ufpe.br/revistas/topicoseducacionais/index

Dossiê "Conflitos, violências, bullying na escola: problemas da convivência potencializado pela pandemia?" DOI: $10.51359 / 2448-0215.2021 .250284$ 
GRAHAM, S.; JUVONEN, J. Self-blame and peer victimization in middle school: an attributional analysis. Developmental Psychology, v. 34, p. 587-638, 1998.

HAWKINS, L.; PEPLER D. J.; CRAIG W. M. Naturalistic observations of peer interventions. Bullying. Social Development, v. 10, n. 4, p. 512-527, 2001.

HODGES, E. V. E.; PERRY, D. G. Personal and interpersonal consequences of victimization by peers. Journal of Personality and Social Psychology, n. 76, p. 677-685, 1996.

IEDE. Interdisciplinaridade e Evidências no Debate Educacional. Como estão as escolas públicas do Brasil? 2019. Disponível em: https://www.portaliede.com.br/wpcontent/uploads/2019/04/Ambiente_Escolar_Questionarios_Saeb2017_Iede.pdf. Acesso em: 09 mar. 2021.

JARES, X. R. Pedagogia da convivência. 2. ed. São Paulo: Palas Athena, 2008.

JUVONEN, J.; GALVAN, A. Peer influence in involuntary social groups: Lessons from research on bullying. In: PRINSTEIN, M.; DODGE, K. (Eds.). Peer influence processes among youth. New York: Guilford Press, 2008. p. 225-244.

LA TAILLE, Y. Vergonha: a ferida moral. São Paulo: Ed. Vozes, 2002.

LA TAILLE, Y. Moral e ética: dimensões intelectuais e afetivas. Porto Alegre: ArtMed, 2006.

LAPA, L. Z. Valentes contra o bullying: a implantação das equipes de ajuda, uma experiência brasileira. 2019. 316 f. Dissertação (Mestrado em Educação Escolar) - Faculdade de Ciências e Letras, Universidade Estadual Paulista, Araraquara, 2019. Disponível em: http:/hdl.handle.net/11449/181907. Acesso em: 10 dez. 2020.

MARQUES, C. A. E.; TAVARES, M. R.; MENIN, M. S. S. Valores Sociomorais. In: TOGNETTA, L. R. P.; MENIN, M. S. S. (Org.). Coleção valores sociomorais: reflexões para a educação. Americana: Adonis, 2017.

MAZZINI, P. F.; BASTOS, C. Z. D. A. A construção dos valores morais na escola por meio de práticas de virtude. Schème: Revista Eletrônica de Psicologia e Epistemologia Genéticas, Marília, v. 8, n. 1, p. 66-97, 2016.

MENESINI, E. et al. Moral emotions and bullying: a cross-national comparison of differences between bullies, victims and outsiders. Aggressive Behavior, v. 29, n. 6, p. 515-530, 2003.

MENESINI, E.; CAMODECA, M. Shame and guilt as behaviour regulators: relationships with bullying, victimization and prosocial behaviour. British Journal of Developmental Psychology, v. 26, p. 183-196, 2008.

MENIN, M. S. S.; BATAGLIA, P. U. R.; MORO, A. Adesão ao valor justiça em crianças e adolescentes. Estudos em Avaliação Educacional, v. 56, n. 24, p. 18-47, 2013.

Revista Tópicos Educacionais, Pernambuco, v. 27, n. 01, p. 98-119, 2021. ISSN: 2448-0215. https://periodicos.ufpe.br/revistas/topicoseducacionais/index

Dossiê "Conflitos, violências, bullying na escola: problemas da convivência potencializado pela pandemia?" DOI: $10.51359 / 2448-0215.2021 .250284$ 
MENIN, M. S. S.; TAVARES, M. R. Por que eleger o tema sobre avaliação de valores. Revista Estudos em Avaliação Educacional, São Paulo, v. 24, n. 56, p. 12-17, set./dez. 2013.

MENIN, M. S. S.; TAVARES, M. R.; MORO, A. Mensurando valores morais: uma pesquisa com alunos do $6^{\mathrm{o}}$ ao $9^{\circ}$ ano do Ensino Fundamental. Revista de Educação Pública, v. 22, n. 49/2, p. $525-549,2013$.

OECD. TALIS 2013 Technical Report. Paris: OECD Publications, 2014. Disponível em: http://www.oecd.org/education/school/talis-2013-results.htm. Acesso em: 09 mar. 2021.

OLWEUS, D. Bully/victim problems in school. Irish Journal of Psychology, v. 18, n. 2, p. 170190, 1997.

OLWEUS, D. Bullying at school: what we know and what we can do. Oxford: Blackwell, 1993.

PELLEGRINI, A. D. Bullying, victimization, and sexual harassment during the transition to middle school. Educational Psychologist, v. 37, n. 3, p. 151-163, 2002.

PIAGET, J. O juízo moral na criança. 3. ed. São Paulo: Summus, 1994.

POZZOLI, T.; GINI, G. Why do bystanders of bullying help or not? a multidimensional model. Journal of Early Adolescence, v. 33, n. 3, p. 315-340, 2013.

RIGBY, K.; SLEE, P. Children's attitudes toward victims. In: TATTUM, D. (Ed.). Understanding and managing bullying. Oxford: Heinemann School Management, 1993. p. 119135 .

SAGONE, E.; LICATA, L. Relazione tra adattamento interpersonale, disimpegno morale, bullismo e comportamento prosociale: una ricerca nella scuola media. Giornale di Psicologia, v. 3, n. 3, p. 247-254, 2009.

SALMIVALLI, C. et al. Bullying as a group process: participant roles and their relations to social status within the group. Aggressive Behavior, v. 22, p. 1-15, 1996.

SALMIVALLI, C.; ISAACS, J. Prospective relations among victimization, rejection, friendlessness, and children's self- and peer-perceptions. Child Development, n. 76, p. 1161-1171, 2005.

SALMIVALLI, C.; PEETS, K. Bullies, victims, and bully-victim relationship. In: RUBIN, K.; BUKOWSKI, W.; LAURSEN, B. Handbook of peer interactions, relationships, and groups. Guilford Press, 2008.

SÁNCHEZ, V.; ORTEGA, R.; MENESINI, E. La competencia emocional de agresores y víctimas de bullying. Anales de Psicología, v. 28, n. 1, 2012.

Revista Tópicos Educacionais, Pernambuco, v. 27, n. 01, p. 98-119, 2021. ISSN: 2448-0215. https://periodicos.ufpe.br/revistas/topicoseducacionais/index

Dossiê "Conflitos, violências, bullying na escola: problemas da convivência potencializado pela pandemia?" DOI: $10.51359 / 2448-0215.2021 .250284$ 
SMITH, P. K. et al. Relationship of children involved in bully-victim problems at school. In: DUCK, S. (Ed.) Understanding relationship process. Newbury Park, C.A.: Sage Publications, 1993. v. 2.

SOUZA, R. A. Quando a mão que acolhe é igual a minha: a ajuda em situações de (cyber)bullying entre adolescentes. 2019. 166 f. Dissertação (Mestrado em Educação Escolar) Faculdade de Ciências e Letras, Universidade Estadual Paulista, Araraquara, 2019. Disponível em: http://hdl.handle.net/11449/181590. Acesso em: 10 dez. 2020.

SUTTON, J.; SMITH, P. K.; SWETTENHAM, J. Bullying and "theory of mind": a critique of the "social skills déficit" view of anti-social behavior. Social developmental, v. 8, p. 117-127, 1999.

TAVARES, M. R. et al. Construção e validação de uma escala de valores sociomorais. Cadernos de pesquisa, São Paulo, v. 46, n. 159, p. 186-210, 2016.

TOGNETTA, L. R. (Org.) Passo a passo para a implementação de um sistema de apoio entre iguais: as equipes de ajuda. Americana: Editora Adonis, 2020a.

TOGNETTA, L. R. P. et al. Bullying e cyberbullying: quando os valores morais nos faltam e a convivência se estremece. Revista Ibero-Americana de Estudos em Educação, Araraquara, v. 12, n. 3, p. 1880-1900, jul./set. 2017. DOI: https://doi.org/10.21723/riaee.v12.n.3.2017.10036

TOGNETTA, L. R. P. Sentimentos e virtudes: um estudo sobre a generosidade ligada às representações de si. 2005. Tese (Doutorado em Psicologia) - Instituto de Psicologia, Universidade de São Paulo, São Paulo, 2005a.

TOGNETTA, L. R. P. Vencer o bullying escolar: o desafio de quem se responsabiliza por educar moralmente. In: TOGNETTA, L. R. P.; VINHA, T. P. (Org.) É possível superar a violência na escola? Construindo caminhos pela formação moral. São Paulo: Editora do Brasil (UNICAMP), 2012.

TOGNETTA, L. R. P. Violência na escola: os sinais de bullying e o olhar necessário aos sentimentos. In: PONTES, A.; DE LIMA, V. S. Construindo saberes em educação. Porto Alegre: Zouk, 2005b.

TOGNETTA, L. R. P.; AVILÉS MARTÍNEZ, J. M.; ROSÁRIO, P. Bullying, un problema moral: representaciones de sí mismo y desconexiones Morales. Revista de educación, n. 373, p. 9-34, 2016.

TOGNETTA, L. R. P.; BOZZA, T. Cyberbullying: quando a violência é virtual - um estudo sobre a incidência e sua relação com as representações de si em adolescentes. In: GUIMARÃES, Á.; PACHECO, Z. Caderno de resumos do I Seminário Violar: problematizando juventudes na contemporaneidade. Campinas, SP: FE/UNICAMP, 2010.

TOGNETTA, L. R. P.; MENIN, M. S. S. (Org.). Reflexões para a educação. 1. ed. Americana, SP: Adonis, 2017. (Coleção: Valores Sociomorais)

Revista Tópicos Educacionais, Pernambuco, v. 27, n. 01, p. 98-119, 2021. ISSN: 2448-0215. https://periodicos.ufpe.br/revistas/topicoseducacionais/index

Dossiê "Conflitos, violências, bullying na escola: problemas da convivência potencializado pela pandemia?" DOI: $10.51359 / 2448-0215.2021 .250284$ 
TOGNETTA, L. R. P.; ROSÁRIO, P. Bullying: dimensões psicológicas no desenvolvimento moral. Estudos em Avaliação Educacional, São Paulo, v. 24, n. 56, p. 106-137, 2013.

TOGNETTA, L. R. P.; VINHA, T. P. Até quando? Bullying na escola que prega a inclusão social. Revista do Centro de Educação, Santa Maria, RS, v. 35, n. 3, p. 449-463, 2010.

TOGNETTA, L. R. P.; VINHA, T. P. Valores em crise: o que nos causa indignação? In: LA TAILLE, Y.; MENIN, M. S. S. Crise de valores ou valores em crise? Porto Alegre, RS: Artmed, 2008.

TOGNETTA, L.R. (Org.). Bullying e convivência em tempos de escolas sem paredes. Americana, SP: Editora Adonis, 2020b.

VINHA, T. P. Reflexões sobre a teoria de Piaget e a construção da autonomia moral. Revista Dois Pontos: teoria e prática em Educação, v. 4, p. 43-46, 1998.

Recebido em abril de 2021.

Aprovado em maio de 2021.

Revista Tópicos Educacionais, Pernambuco, v. 27, n. 01, p. 98-119, 2021. ISSN: 2448-0215.

https://periodicos.ufpe.br/revistas/topicoseducacionais/index

Dossiê "Conflitos, violências, bullying na escola: problemas da convivência potencializado pela pandemia?" DOI: $10.51359 / 2448-0215.2021 .250284$ 